\title{
Is cancer survival associated with cancer symptom awareness and barriers to seeking medical help in England? An ecological study
}

\author{
Maja Niksic ${ }^{*}, 1$, Bernard Rachet ${ }^{2}$, Stephen W Duffy ${ }^{3}$, Manuela Quaresma ${ }^{2}$, Henrik Møller ${ }^{1}$ and \\ Lindsay JL Forbes ${ }^{1}$
}

${ }^{1}$ Cancer Epidemiology and Population Health, Cancer Studies Research Division, King's College London, Bermondsey Wing, 3rd floor, Guy's Hospital, Great Maze Pond, London SE1 9RT, UK; ${ }^{2}$ Cancer Research UK Cancer Survival Group, Department of Non-Communicable Disease Epidemiology, Faculty of Epidemiology and Population Health, London School of Hygiene and Tropical Medicine, Keppel Street, London WC1E 7HT, UK and ${ }^{3}$ Centre for Cancer Prevention, Wolfson Institute of Preventive Medicine, Barts and The London School of Medicine and Dentistry, Queen Mary University of London, Charterhouse Square, London EC1M 6BQ, UK

Background: Campaigns aimed at raising cancer awareness and encouraging early presentation have been implemented in England. However, little is known about whether people with low cancer awareness and increased barriers to seeking medical help have worse cancer survival, and whether there is a geographical variation in cancer awareness and barriers in England.

Methods: From population-based surveys ( $n=35308)$, using the Cancer Research UK Cancer Awareness Measure, we calculated the age- and sex-standardised symptom awareness and barriers scores for 52 primary care trusts (PCTs). These measures were evaluated in relation to the sex-, age-, and type of cancer-standardised cancer survival index of the corresponding PCT, from the National Cancer Registry, using linear regression. Breast, lung, and bowel cancer survival were analysed separately.

Results: Cancer symptom awareness and barriers scores varied greatly between geographical regions in England, with the worst scores observed in socioeconomically deprived parts of East London. Low cancer awareness score was associated with poor cancer survival at PCT level (estimated slope $=1.56,95 \% \mathrm{Cl}: 0.56 ; 2.57$ ). The barriers score was not associated with overall cancer survival, but it was associated with breast cancer survival (estimated slope $=-0.66,95 \% \mathrm{Cl}:-1.20 ;-0.11$ ). Specific barriers, such as embarrassment and difficulties in arranging transport to the doctor's surgery, were associated with worse breast cancer survival.

Conclusions: Cancer symptom awareness and cancer survival are associated. Campaigns should focus on improving awareness about cancer symptoms, especially in socioeconomically deprived areas. Efforts should be made to alleviate barriers to seeking medical help in women with symptoms of breast cancer.

Cancer accounts for more than 130000 deaths each year in England (Office for National Statistics, 2012a). Survival for most types of cancer is lower in England than in comparable Western European countries (Berrino et al, 2007), and in other high-income countries, such as Canada and Australia (Coleman et al, 2011). The National Health Service (NHS) in England has introduced several cancer plans, highlighting early diagnosis as a key strategy to improve cancer survival (Department of Health, 2000, 2011, 2014). Since Improving Outcomes: A Strategy for Cancer in 2011, more than $£ 450$ million has been invested in raising cancer awareness and encouraging early diagnosis in England (Department of Health, 2014). A number of 'Be Clear on Cancer' campaigns were developed to improve recognition of early symptoms and encourage prompt visits to the doctor for the most common types

*Correspondence: M Niksic; E-mail: maja.niksic@kcl.ac.uk

Received 18 November 2015; revised 13 July 2016; accepted 17 July 2016; published online 18 August 2016

(c) 2016 Cancer Research UK. All rights reserved 0007-0920/16

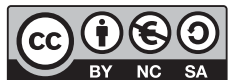


of cancer, such as breast, lung, and bowel cancer (Cancer Research UK, 2015). The underlying assumption was that survival would be improved if people recognised symptoms early and sought medical help before developing advanced-stage cancer. Short-term survival is particularly sensitive to stage of disease and therefore to timeliness of cancer diagnosis.

It is not clear what effect, if any, cancer awareness and barriers to help seeking have on cancer survival. The most appropriate research design to address this question would be a prospective, cohort study examining the predictive value of symptom recognition or barriers to help seeking on cancer survival. Such a study has not yet been carried out. It is also difficult to assess the effects of intermediary factors, such as time from the onset of symptoms to presentation, time from presentation to starting a treatment, stage of disease, and types of treatment. Ironmonger et al (2014) evaluated the first national campaign and a regional campaign in England, both aimed at raising public awareness of a persistent cough as a lung cancer symptom. They reported an increase in cancer awareness, a shift to earlier stage at diagnosis, and a higher surgical resection rate after both campaigns, compared with 1 year before. Data on survival were available only for the regional campaign, and suggested a statistically nonsignificant increase in 1-year survival in the pilot compared with control areas.

Evidence suggests a wide geographical variation in cancer survival in England, with lower survival in the north compared with the south of the country (Quaresma et al, 2011; Walters et al, 2011). Quaresma et al (2011) showed that the geographical variation in 1-year cancer survival at primary care trust (PCT) level is constant year- on year, from 1996 to 2009. The PCTs were the statutory NHS bodies, structured as small geographical areas, responsible for commissioning and providing most health services in England until 2013 (NHS, 2012). Walters et al (2011) reported the same geographical patterns, with generally lower cancer survival in northern England, for patients diagnosed between 1991 and 2006, using Cancer Network areas. These studies analysed survival from the most common types of cancer, such as lung, breast, and bowel.

To explore reasons for variation in cancer survival between countries with similar health-care systems, including Australia, Canada, Denmark, Norway, Sweden, and the United Kingdom, Forbes et al (2013) examined differences in cancer awareness and barriers to help seeking. Although the United Kingdom, with the lowest cancer survival, had low average cancer awareness and the highest barriers, there was no consistent pattern across the participating countries. For example, Denmark, also with poor cancer survival, had low levels of barriers. However, it may be difficult to detect any patterns at an international level. The assessment of differences in cancer awareness and barriers by much smaller geographical region in a single country may offer a more salient explanation of cancer survival differences. This study aimed to identify how cancer symptom awareness and barriers to help seeking vary by small geographical region (PCT) in England, and whether average levels of awareness and barriers are associated with cancer survival at the PCT level.

\section{MATERIALS AND METHODS}

Material. Data from population-based surveys, using the Cancer Research UK Cancer Awareness Measure across England $(n=49270)$, were linked with cancer survival data from the National Cancer Registry at the Office for National Statistics. These two data sets were linked based on matching by the relevant geographical area (PCT) in England. To make the matching procedure more reliable we used cancer survival data of patients diagnosed in 2010 only, because most CAM surveys were conducted in that year (range: 2009-2011). This meant that both patients and survey participants would have been exposed to the same media health messages and local cancer awareness campaigns, delivered in their area of residence up to 2010.

On one side, we used data from the surveys, described in detail elsewhere (Niksic et al, 2015), carried out in 92 PCTs out of the 151 PCTs in England at the time. The response rate was 51\%. The surveys questions used to assess cancer symptom awareness (summed up recognition of 9 cancer symptoms) and barriers to help seeking (summed up reporting of 10 barriers to help seeking) are available in Supplementary Material.

To allow reliable calculations of awareness and barriers scores, we included only 52 PCTs, which had at least 90 participants in total, with available data in each sex and age category (15-44; 45$54 ; 55-64 ; 65-74$; and $75+$ years). To calculate the symptom awareness score, for each participant we added up the positive responses ('Yes') to the questions about the recognition of nine cancer symptoms (Niksic et al, 2015). We then calculated the arithmetic mean of this score for each combination of PCT, sex, and age group. We took the same approach with calculating the barriers score, using positive responses ('Yes often' or 'Yes sometimes') to questions about 10 barriers to help seeking. To standardise the awareness and barriers scores by age and sex, we used the age and sex weights developed by the Cancer Research UK Cancer Survival Group, at London School of Hygiene and Tropical Medicine. The same weights were also used for the calculation of cancer survival index (and site-specific indices). The only difference between these weights was that cancer survival indices were also weighted for the type of cancer. This made the comparison between the awareness and barriers score and cancer survival indices more reliable. It also allowed us to avoid using the same weights for the elderly and the young people living in each PCT who have different risks of being diagnosed with cancer and different cancer survival. The same approach was used with calculating individual symptoms and barriers.

On the other side, we used data from the National Cancer Registry to calculate net cancer survival. Net survival was defined as survival from a cancer of interest in the absence of death from other causes, estimated from population life tables (Perme et al, 2012). The life tables were stratified by every year of age, sex, and socioeconomic deprivation categories for the calendar years 2010-2011, and developed by Cancer Research UK Cancer Survival Group, at the London School of Hygiene and Tropical Medicine. The survival index was calculated as 1-year net survival for all cancers combined, except non-melanoma skin and prostate cancer, standardised for type of cancer, sex, and age, in five age categories (15-44; 45-54; 55-64; 65-74; and $75+$ years) for patients diagnosed in 2010 and followed up until 2011. Patients diagnosed with non-melanoma skin cancer were excluded because these malignancies are rarely fatal and extremely rarely linked with metastases (NCIN, 2013). Registries in the United Kingdom have incomplete data on non-melanoma skin cancer that is often underreported, and many patients are treated topically without pathological verification and in the private sector (Goodwin et al, 2004; NCIN, 2013). Prostate cancer was excluded because the widespread introduction of prostate-specific antigen (PSA) testing since the early 1990s introduced difficulties in the interpretation of survival trends (Pashayan et al, 2006). The exclusion of nonmelanoma skin cancer and prostate cancer is the common procedure in calculation of the cancer survival index in England, published annually by the ONS (Office for National Statistics, 2012b).

This index was designed to support the evaluation of the effects of early diagnosis, and to provide a single summary measure of cancer survival, for the purpose of monitoring the effectiveness of the health-care system (Quaresma et al, 2015). Breast (women only), bowel, and lung cancer survival indices were calculated using 
the same approach. These types of cancer were selected because they are associated with the highest incidence and the highest mortality in Europe (Ferlay et al, 2013).

The total number of cancer patients used to construct the survival index and site-specific indices was 133413 , the number or residents in PCTs included in our analysis who were diagnosed with cancer in 2010. Out of this number, 13475 (10\%) were female breast cancer patients, 21902 (16\%) were bowel cancer patients, $21510(n=16 \%)$ were lung cancer patients, and 76526 (57\%) were patients diagnosed with other types of cancer. The cancer survival indices at PCT level were linked to the cancer awareness and barriers measures by the corresponding PCT.

Statistical analysis. The awareness and barriers scores were analysed as continuous variables, and their association with the cancer survival index was assessed using scatter plots and linear regression (at $P<0.05$ level). The survival index was the dependent variable. Scatter plots were also used to visually assess the association between breast, bowel, and lung cancer survival, and their cancer-specific symptoms, including 'unexplained lump or swelling', 'persistent cough or hoarseness', and 'change in bowel or bladder habits', respectively. Associations between cancer survival indices and individual cancer symptoms and individual barriers were also assessed using linear regression. In regression models, each PCT was weighted using the inverse variance of the cancer survival estimate. We defined different levels of the barriers score based on the interquartile range (IQR). We considered barriers below 25th percentile as 'low', between 25th and 75th percentile as 'intermediate' barriers, and above 75th percentile as 'high' barriers. The same procedure was used for the awareness score. Maps were also developed using 25th and 75th percentiles to determine the cutoff points for low, intermediate, and high scores. We calculated the statistical power to detect the effects in our regression analysis using a post hoc power calculator (http:// clincalc.com/Stats/Power.aspx), and reliability of cancer awareness and barriers scores between PCTs using one-way ANOVA. We analysed data using Stata 14.0 (2015; Stata 14.0 Statistical Software, College Station, TX, USA) and ArcGIS for Desktop Advanced 10.3 software (Environmental Systems Research Institute, 2014).

\section{RESULTS}

Our data set included 52 PCTs spread across England (Table 1). The mean cancer symptom awareness score was 7.2 (range: 4.88.3, IQR: 6.9-7.6). The mean barriers to help-seeking score was 1.7 (range: 0.6-3.1, IQR: 1.4-1.8). The 1-year cancer survival index had a mean value of 66.9 (range: 60.5-71.7).

Geographical variation in cancer awareness and barriers to help seeking in England. The lowest cancer awareness scores were observed in Tower Hamlets (4.8), Newham (5.5), Redbridge (6.4), Gloucestershire (6.5), and Lambeth (6.5). The highest awareness scores were observed in Peterborough (8.3), Bedfordshire (8.1), Great Yarmouth and Waveney (8.1), and Cambridgeshire (8.0) (Figure 1).

In England, different PCTs were ranked according to their socioeconomic deprivation based on the income domain of the English indices of Deprivation (Department for Communities and Local Government, 2011). The PCTs ranked as some of the most socioeconomically deprived were: Newham and Tower Hamlets in East London, Bradford and Airedale and Kirklees in Yorkshire, Lambeth and City and Hackney in London, and Hampshire in Southern coast of England. The PCTs ranked as some of the least socioeconomically deprived were: Herefordshire in West Midlands, Bedfordshire in the East of England, Richmond and Twickenham in London, and Great Yarmouth and Waveney in the East of England.
The highest barriers scores were observed in Tower Hamlets (3.1), Kirklees (3.1), Bradford and Airedale (3.0), and Newham (2.7). The lowest barriers scores were observed in North Tyneside (0.6), Northamptonshire (0.8), Newcastle (0.9), and Herefordshire (1.1) (Figure 2).

Cancer awareness and barriers scores in relation to cancer survival. There were large differences between survival from different types of cancer: breast cancer survival ranged from $93 \%$ to $99 \%$, bowel cancer survival ranged from $67 \%$ to $81 \%$, and lung cancer survival ranged from $18 \%$ to $42 \%$.

Scatter plots showed the position of each PCT with regard to their cancer survival and cancer awareness score or recognition of cancer-specific symptoms (Figure 3); and cancer survival and barriers score (Figure 4). There was a considerable variation in assessed variables across PCT areas. We observed a trend with the best scores in PCTs such as Bedfordshire and Cambridgeshire, and the worst scores in Tower Hamlets and Newham PCTs. The outliers in most scatter plots were Tower Hamlets and Newham PCTs, but even after excluding these outliers, similar trends remained in the scatter plots.

The association between the cancer awareness score and the cancer survival index was statistically significant (estimated slope $=1.56,95 \%$ CI: $0.56 ; 2.57, P=0.01$ ) (Table 2). Each additional symptom recognised was associated with a $1.56 \%$ increase in the cancer survival index. Recognition of seven out of nine individual symptoms was statistically significantly associated with a slight increase in cancer survival index (Table 2). For example, for every $1 \%$ increase in the recognition of unexplained lump or swallowing among people living in these PCTs, there was a 0.15 increase in cancer survival index. For every $1 \%$ increase in the recognition of unexplained weight loss among people living in these PCTs, there was a 0.13 increase in cancer survival index (Table 2). We found no trends (Figure 3 ) or statistically significant associations (Table 2) between survival from breast, lung, or bowel cancer, and the awareness score or recognition of each cancer symptom.

The barriers score was not associated with the cancer survival index (estimated slope $=-0.14,95 \% \mathrm{CI}:-1.28 ; 0.99, P=0.80$ ), but it was associated with breast cancer survival: each additional barrier reported was associated with $0.66 \%$ decrease in the breast cancer survival (estimated slope $=-0.66,95 \% \mathrm{CI}:-1.20$; -0.11 , $P=0.02$ ) (Table 2). Most individual barriers had an inverse association with breast cancer survival. We found no statistically significant associations between the barriers score or individual barriers and lung and bowel cancer survival. Similar statistically significant associations were obtained after we excluded from regression models the two outliers, Tower Hamlets and Newham PCTs (data available on request).

\section{DISCUSSION}

We found geographical variation in cancer symptom awareness and barriers to help seeking across England, with the lowest scores observed in socioeconomically deprived parts of East London. Low cancer symptom awareness was associated with poor cancer survival index for all cancers combined, and high barriers to seeking medical help were associated with poor survival from breast cancer at PCT level in England.

Strengths and limitations. This is the first study to examine geographical variation in cancer awareness and barriers to help seeking in England and to link these with cancer survival data. All measures, predictors, and outcomes were standardised using the same age- and sex-standardised weights. This means that the cancer awareness and barriers score in each PCT were weighted differently depending on the age and sex structure of the survey 
Table 1. Primary care trusts (PCTs) included in the analysis, with cancer awareness and barriers scores, cancer survival index (all cancers combined, year 2010), weights applied in regression analyses, and number of survey participants and cancer patients per PCT

\begin{tabular}{|c|c|c|c|c|c|c|c|c|c|}
\hline Region & Primary Care Trust & ID & $\begin{array}{c}\text { Awareness } \\
\text { score }^{a}\end{array}$ & $\begin{array}{c}\text { Barriers } \\
\text { score }^{a}\end{array}$ & $\begin{array}{c}\text { Number of } \\
\text { participants }\end{array}$ & $\begin{array}{l}\text { Cancer } \\
\text { survival } \\
\text { index }(\%)\end{array}$ & $\begin{array}{l}\text { Variance of } \\
\text { cancer } \\
\text { survival index }\end{array}$ & Weight $^{b}$ & $\begin{array}{c}\text { Number of } \\
\text { patients }\end{array}$ \\
\hline \multirow[t]{6}{*}{ Anglia } & Bedfordshire & 1 & 8.1 & 1.4 & 671 & 65.8 & 0.10 & 6.7 & 2848 \\
\hline & Cambridgeshire & 2 & 8.0 & 1.7 & 679 & 70.9 & 0.07 & 10.0 & 4603 \\
\hline & $\begin{array}{l}\text { Great Yarmouth and } \\
\text { Waveney }\end{array}$ & 3 & 8.1 & 1.3 & 518 & 68.1 & 0.10 & 7.2 & 2143 \\
\hline & Norfolk & 4 & 7.5 & 1.8 & 498 & 68.5 & 0.03 & 22.2 & 7064 \\
\hline & Peterborough & 5 & 8.3 & 1.5 & 537 & 66.1 & 0.19 & 3.4 & 1148 \\
\hline & Suffolk & 6 & 8.0 & 1.8 & 624 & 69.1 & 0.07 & 11.0 & 4960 \\
\hline \multirow[t]{4}{*}{ Central South Coast } & Hampshire & 7 & 7.8 & 1.5 & 387 & 69.9 & 0.04 & 16.4 & 9190 \\
\hline & Isle of Wight & 8 & 7.8 & 1.6 & 378 & 66.5 & 0.17 & 4.1 & 1149 \\
\hline & Portsmouth City & 9 & 7.8 & 1.5 & 342 & 65.5 & 0.16 & 4.1 & 1210 \\
\hline & Southampton City & 10 & 7.3 & 1.6 & 343 & 65.5 & 0.22 & 2.6 & 1314 \\
\hline East Midlands & Northamptonshire & 11 & 6.9 & 0.8 & 1939 & 66.5 & 0.07 & 9.0 & 4182 \\
\hline \multirow[t]{5}{*}{ Humber \& Yorkshire Coast } & East Riding & 12 & 7.7 & 1.4 & 1212 & 69.2 & 0.09 & 8.2 & 2751 \\
\hline & Hartlepool & 13 & 7.3 & 1.5 & 94 & 65.4 & 0.29 & 2.4 & 721 \\
\hline & Hull & 14 & 7.4 & 1.4 & 936 & 65.2 & 0.12 & 5.4 & 1621 \\
\hline & North East Lincolnshire & 15 & 7.7 & 1.6 & 1007 & 67.6 & 0.17 & 4.2 & 1166 \\
\hline & North Lincolnshire & 16 & 7.4 & 1.6 & 1081 & 67.9 & 0.17 & 4.4 & 1172 \\
\hline \multirow[t]{3}{*}{ Kent and Medway } & Eastern and Coastal Kent & 17 & 7.4 & 1.6 & 1058 & 65.4 & 0.07 & 10.1 & 5469 \\
\hline & Medway & 18 & 7.2 & 1.9 & 1015 & 61.1 & 0.14 & 5.1 & 1617 \\
\hline & West Kent & 19 & 7.5 & 1.8 & 775 & 66.5 & 0.07 & 9.0 & 4378 \\
\hline \multirow[t]{2}{*}{ Mount Vernon } & Hertfordshire & 20 & 7.3 & 1.2 & 777 & 67.7 & 0.05 & 12.7 & 7241 \\
\hline & Luton & 21 & 6.8 & 1.3 & 378 & 63.8 & 0.19 & 3.7 & 1154 \\
\hline \multirow[t]{7}{*}{ North East London } & Barking and Dagenham & 22 & 6.9 & 1.8 & 245 & 60.5 & 0.32 & 1.7 & 879 \\
\hline & City and Hackney & 23 & 6.7 & 2.2 & 245 & 65.1 & 0.25 & 2.8 & 933 \\
\hline & Havering & 24 & 7.1 & 2.1 & 360 & 65.5 & 0.13 & 4.9 & 1685 \\
\hline & Newham & 25 & 5.5 & 2.7 & 193 & 61.7 & 0.21 & 3.0 & 954 \\
\hline & Redbridge & 26 & 6.4 & 1.8 & 318 & 64.3 & 0.16 & 3.9 & 1295 \\
\hline & Tower Hamlets & 27 & 4.8 & 3.1 & 258 & 65.1 & 0.37 & 1.7 & 870 \\
\hline & Waltham Forest & 28 & 6.6 & 1.5 & 274 & 63.8 & 0.24 & 2.6 & 1159 \\
\hline \multirow[t]{4}{*}{ North Trent } & Barnsley & 29 & 7.7 & 1.7 & 795 & 66.0 & 0.18 & 3.7 & 1727 \\
\hline & Bassetlaw & 30 & 7.7 & 1.7 & 811 & 65.1 & 0.36 & 1.9 & 809 \\
\hline & Doncaster & 31 & 7.4 & 1.7 & 1217 & 66.3 & 0.12 & 4.9 & 2233 \\
\hline & Sheffield & 32 & 7.6 & 1.7 & 2993 & 69.4 & 0.09 & 6.9 & 3583 \\
\hline \multirow[t]{5}{*}{ North of England } & Lincolnshire & 33 & 7.9 & 1.5 & 95 & 69.7 & 0.07 & 10.0 & 5762 \\
\hline & Middlesbrough & 34 & 7.0 & 1.3 & 298 & 65.8 & 0.23 & 3.1 & 1009 \\
\hline & Newcastle & 35 & 7.3 & 1.0 & 713 & 67.3 & 0.11 & 5.9 & 1875 \\
\hline & North Tyneside & 36 & 7.5 & 0.6 & 242 & 66.9 & 0.16 & 4.1 & 1538 \\
\hline & Northumberland & 37 & 7.8 & 1.1 & 283 & 69.0 & 0.11 & 6.0 & 2412 \\
\hline \multirow[t]{2}{*}{ South East London } & Bexley & 38 & 7.2 & 2.7 & 155 & 67.4 & 0.13 & 5.3 & 1495 \\
\hline & Lambeth & 39 & 6.5 & 1.2 & 2144 & 66.3 & 0.28 & 2.3 & 1159 \\
\hline \multirow[t]{5}{*}{ South West London } & Croydon & 40 & 7.3 & 1.8 & 824 & 67.8 & 0.19 & 3.2 & 1834 \\
\hline & Kingston & 41 & 7.1 & 1.8 & 830 & 68.8 & 0.26 & 2.5 & 808 \\
\hline & $\begin{array}{l}\text { Richmond and } \\
\text { Twickenham }\end{array}$ & 42 & 7.5 & 1.9 & 839 & 71.7 & 0.30 & 2.2 & 972 \\
\hline & Sutton and Merton & 43 & 7.2 & 2.0 & 1644 & 69.1 & 0.09 & 7.2 & 2146 \\
\hline & Wandsworth & 44 & 6.7 & 2.4 & 841 & 68.7 & 0.17 & 4.2 & 1304 \\
\hline \multirow[t]{3}{*}{ Three Counties } & Gloucestershire & 45 & 6.5 & 2.2 & 307 & 68.1 & 0.07 & 9.1 & 4283 \\
\hline & Herefordshire & 46 & 7.1 & 1.1 & 290 & 67.5 & 0.16 & 4.3 & 1333 \\
\hline & Worcestershire & 47 & 6.6 & 1.3 & 386 & 68.1 & 0.09 & 7.2 & 3982 \\
\hline \multirow[t]{5}{*}{ Yorkshire } & Bradford and Airedale & 48 & 6.8 & 3.0 & 336 & 68.4 & 0.08 & 8.8 & 2860 \\
\hline & Kirklees & 49 & 7.0 & 3.1 & 346 & 66.8 & 0.09 & 7.8 & 2524 \\
\hline & Leeds & 50 & 7.3 & 2.4 & 272 & 69.1 & 0.06 & 10.2 & 4947 \\
\hline & North Yorkshire and York & 51 & 7.5 & 1.6 & 1279 & 69.9 & 0.04 & 18.6 & 5590 \\
\hline & Wakefield District & 52 & 7.6 & 2.6 & 226 & 67.1 & 0.10 & 6.7 & 2352 \\
\hline Total & & & & & 35308 & & & & 133413 \\
\hline \multicolumn{10}{|c|}{ 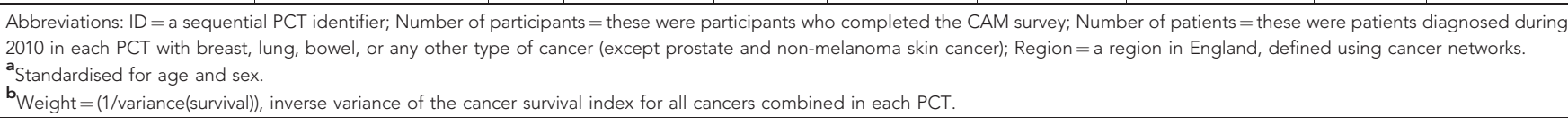 } \\
\hline
\end{tabular}


population in each PCT. The cancer survival indices were standardised by age, sex, and type of cancer in each PCT to adjust for changes over time in the distribution of cancer patients in these categories. This approach was necessary because cancer survival varies widely depending on these factors (Quaresma et al, 2012). Therefore, the cancer survival indices were not affected by changes over time in the proportion of cancers of different lethality by sex, such as an increase in breast cancer and a reduction of lung cancer incidence. In addition, the survival indices were not affected by different age distributions of the cancer patient population or a shift in the proportion of men and women diagnosed with a given type of cancer (Quaresma et al, 2012; Office for National Statistics, 2012c). We analysed only PCTs with $90+$ participants and available data in all sex and age groups to allow reliable calculations of the scores. A validated measure of public cancer awareness (Stubbings et al, 2009) was used to interview participants included in a large population-based sample.

The matching of surveys with survival data of patients diagnosed in 2010 when most of the surveys were carried out reduced a possible bias that would happen if patients had more opportunities to improve their cancer awareness than survey participants. For example, several regional campaigns were run in England during 2011, and the first large national campaigns, aimed at improving awareness about lung and bowel cancer symptoms, were introduced in 2012 (Ironmonger et al, 2014). To the best of our knowledge there were no large-scale awareness raising campaigns in England before 2010. In fact, most of the CAM questionnaires were used by cancer networks as a preliminary assessment before launching various cancer awareness campaigns. We used a 1-year cancer survival that is the most commonly used proxy measure for late presentation (Møller et al, 2011). This is because most excess deaths in the English patients diagnosed with breast (Møller et al, 2010), lung (Cheyne et al, 2013), and bowel cancer (Møller et al, 2012) occur in the first year after diagnosis. Our study provides some support to the NAEDI hypothesis that proposed that the main reasons behind late diagnosis, associated with poor survival, are low cancer awareness and increased barriers to help seeking (Richards, 2009; Hiom, 2015).

As with any ecological study, our study may be subject to what has been called the ecological fallacy that can occur if we assume that inferences based on group-level analyses are applicable at the individual level (Piantadosi et al, 1988). For example, it would be incorrect to assume that by simply increasing awareness about an additional cancer symptom would mean that a person can expect an increase in cancer survival by 1.65 percentage point (if and when cancer is diagnosed). If a woman no longer feels embarrassment in relation to changes in her breasts following a campaign, it does not mean that her expected survival from breast cancer will be automatically increased by 0.6 percentage points. In addition, the possibility that these associations may be stronger or weaker at the level of individual cancer patients cannot be excluded. Although our findings are not directly applicable to individual people, they outlined an overall pattern of low cancer survival in small geographical areas with low cancer symptom awareness. As such, our findings can be used as a starting point in investigations of the complex relationship between symptom awareness, barriers to help seeking, and cancer survival. This is essential before embarking on a large and complex investigation based on individual-level data. Marmot (1998) argues that ecological analyses are a useful way to explore the relationship between social environment and health, particularly as effective policies are delivered at a community-wide level rather than individual level.

Our results might not be generalised nationally, because we included only a third of all PCTs. However, we included a wide range of environmentally and socioeconomically diverse PCTs across the country. We have not adjusted our analyses for socioeconomic deprivation or ethnicity for a number of reasons. First, at the time when we conducted the analysis, survival data of different ethnic groups by PCT were not available to us. Therefore, it was not possible to include this factor in our analysis. Second, our units of analysis were PCTs, and there was a wide variation of socioeconomic deprivation within each PCT. Calculating a single deprivation score for each PCT may not be valid. This is because on average there are $\sim 100000$ people living in each PCT, and some PCTs had over 250000 residents such as Brighton and Hove (Bojke et al, 2001). Adjusting the PCTs for their average socioeconomic status may not accurately capture material or social resources, especially among culturally and ethnically diverse groups. Most large cities in England, such as London, Manchester, or Lancaster, have some poor people living in affluent areas, and vice versa, with contrasting housing types in the same neighbourhood, ranging from Victorian semi-detached houses and maisonettes to less popular council flats and 'towers' (Cattell, 2001; Popay et al, 2003). Therefore, adjusting each geographical area for its average level of socioeconomic deprivation is not warranted, especially if there are large gaps between the affluent and poor residents in that area.

Third, our surveys had a substantial proportion of participants with missing data on socioeconomic deprivation. If we had decided to use data on socioeconomic deprivation to calculate the cancer awareness and barriers scores, the number of units in our analysis would be reduced to 22 only. This is because we would have to remove 30 PCTs, because they did not have participants in all five categories of socioeconomic deprivation. However, we used population life tables that may in part overcome the fact that socioeconomic deprivation was not accounted for. These life tables took into account different mortality rates of a different population groups living in these PCT during the years 2010 and 2011 and, for example, controlled for the fact that the elderly men, with low socioeconomic position, have high mortality rates. In addition, the use of age- and sex-standardised weights also accounted for some of the differences in sociodemographic distribution of people living in these PCTs.

With statistical power of $80 \%$ we were able to detect regression coefficients over 1.44 for cancer awareness and over 0.36 for barriers score in relation to the overall cancer survival index. For breast cancer survival, with statistical power of $80 \%$ we were able to detect regression coefficients over 0.79 for cancer awareness and over 0.17 for barriers score. For lung cancer survival, with statistical power of $80 \%$ we were able to detect regression coefficients over 2.76 for cancer awareness and over 0.62 for barriers score. For bowel cancer survival, with statistical power of $80 \%$ we were able to detect regression coefficients over 2.08 for cancer awareness and over 0.50 for barriers score. It is possible that some of our results were not statistically significant because of lack of power, rather than no association. However, it is worth noting that the weighting in the regression model to some extent mitigates the lack of power.

It is important to note that the scores were standardised by age group and sex that would reduce the within-PCT variability. The reliability of the group-level barriers scores was at $\sim 0.80$ for each age and sex combination, with the exception of the $75+$ age group (0.23 in men and 0.50 in women). For awareness scores, their reliability was above 0.80 for each age and sex combination, with the exception of elderly men (0.55) and elderly women (0.53). The relatively low reliability among elderly is related to the small number of participants in the $75+$ age group. This suggests an overall reliability of the PCT-level scores standardised on age and sex.

Comparison with existing literature. Cancer symptom awareness and barriers to help seeking varied greatly between geographical areas in England, but we did not observe a north-south divide in these scores. The worst scores were observed in socioeconomically deprived parts of East London, such as Tower Hamlets and Newham. There is ample evidence that socioeconomically deprived 

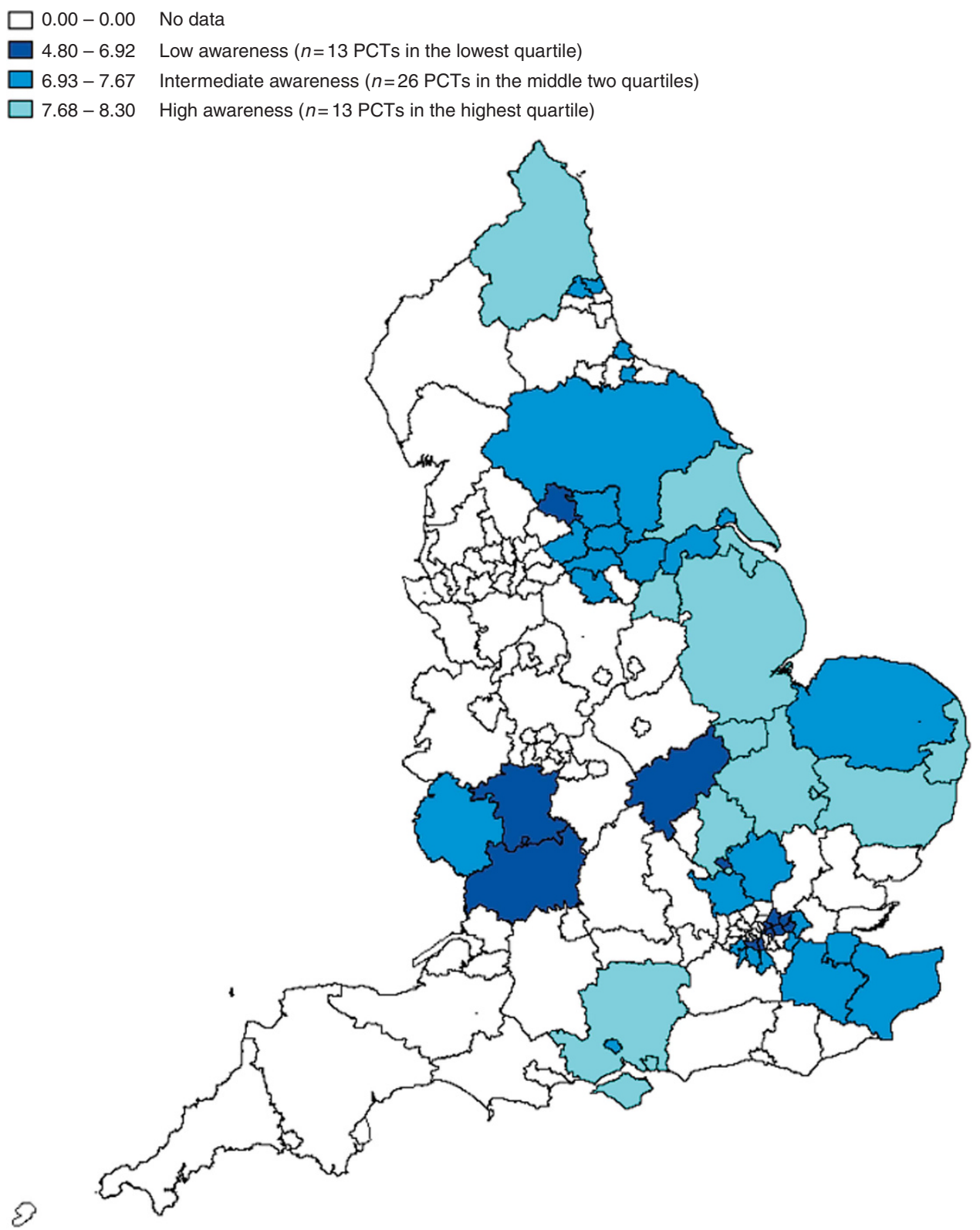

Figure 1. Cancer symptom awareness score by PCT in England.

people in England tend to have low cancer symptom awareness and numerous reasons to deter them from seeking medical help, including embarrassment or difficulties in arranging transport to the doctor's surgery (Robb et al, 2009; Waller et al, 2009; Niksic et al, 2015). A recent Danish study corroborated the findings that socioeconomic deprivation is strongly associated with increased barriers to help seeking (Hvidberg et al, 2014). Underprivileged people are also more likely to pursue an unhealthy lifestyle, including smoking and low physical activity (Marmot et al, 1991), that act to 'normalise' early symptoms of disease (Dixon-Woods et al, 2006). They may also feel embarrassed to discuss their symptoms with their doctor because of perceived social distance and status differences.

Another possible explanation for our findings is the role of ethnic minority background, one of the factors contributing to poor recognition of symptoms and increased barriers to help seeking (Forbes et al, 2011; Niksic et al, 2016). A recent study found that ethnic minorities in England had lower cancer symptom awareness and more widespread barriers to seeking medical help than White participants (Niksic et al, 2016). Another study carried out in East London also reported that South Asian and Black women had significantly lower breast cancer awareness than White women (Forbes et al, 2011). Emotional barriers to seeking medical help, such as embarrassment and lack of confidence to talk to the doctor, were highest among South Asian women. These differences could not be explained by different levels of educational attainment or socioeconomic deprivation. Socioeconomically deprived areas often have higher proportion of ethnic minorities, and these two factors in combination may have an amplified effect on cancer awareness and barriers to help seeking.

Low cancer awareness was associated with low cancer survival at PCT level, with the worst results observed in Tower Hamlets and Newham. These boroughs of Inner North-East London, together with Hackney, have been described as 'the unhealthiest place in Britain', with high levels of unemployment, large ethnic diversity, low levels of social cohesion, and the largest population growth in the country (East London NHS Trust, 2013). People living in the 
$0.00-0.00 \quad$ No data

$0.59-1.43$ Low barriers ( $n=13$ PCTs in the lowest quartile)

$1.44-1.87$ Intermediate barriers ( $n=26$ PCTs in the middle two quartiles)

$1.88-3.01$ High barriers ( $n=13$ PCTs in the highest quartile)

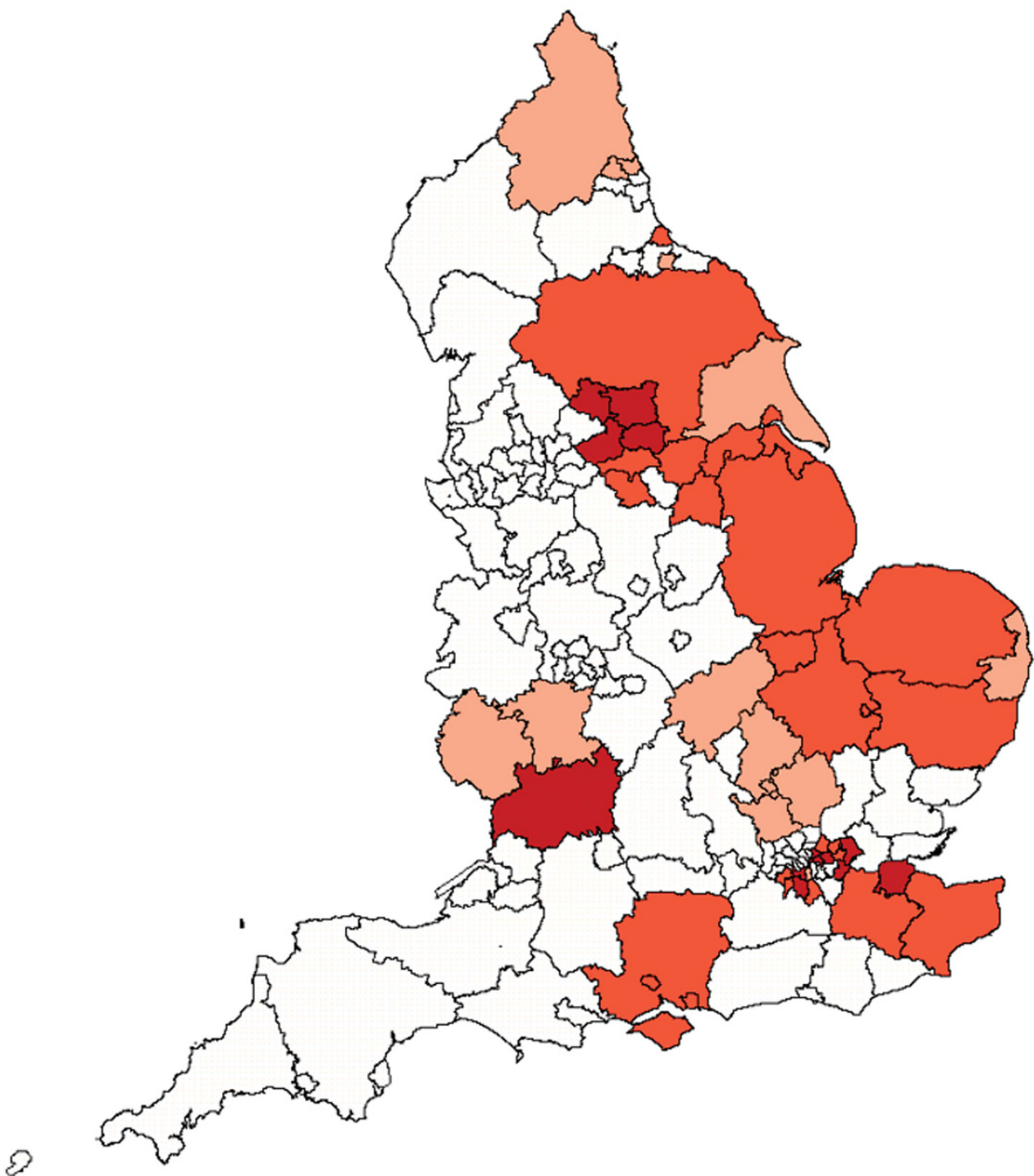

Figure 2. Barriers to help-seeking score by PCT in England.

same PCT area are likely to share aspects of their social and lifestyle patterns, and access to educational and health-care facilities, making their health outcomes more similar than those of people from different PCTs (Nur et al, 2015). A term 'place effect' was coined to describe the extent of area effects on individuals' health (Macintyre et al, 2002). If symptom awareness and cancer survival are to be improved, then it can be argued that place effects need to be taken into account. Campaigns may be more effective if they are culturally sensitive and socially inclusive, with a clear and simple message, translated into languages frequently spoken in the community, and if health-care provision, in terms of both units and personnel, is increased in areas with rapidly growing population. Socioeconomically deprived areas that have poor cancer survival (Coleman et al, 2004; Rachet et al, 2010) could benefit most from awareness rising campaigns. A recent NHS Health and Wellbeing Strategy is an example of the area-specific approach to improve health outcomes that includes reducing the risks of developing cancer (East London NHS Trust, 2013).

We found no strong evidence that recognition of the cancerspecific symptoms were associated with survival from the corresponding cancers. People may perceive these symptoms, such as 'persistent cough', as temporary and attribute them to noncancer causes like smoking, having a cold, or an allergy. As an alternative explanation, the role of 'symptom clusters' has also been implicated. Early symptoms of breast, bowel, or lung cancer often occur in clusters rather than in isolation. A symptom cluster is a relatively stable group of two or more related symptoms, occurring simultaneously and independently from other symptom clusters (Kim et al, 2005). For example, the cluster of lung cancer symptoms may include thoracic pain, cough, hemoptysis, and vomiting (Hamilton et al, 2005a). The cluster of bowel cancer symptoms may include rectal bleeding, abdominal pain, diarrhoea, and weight loss (Hamilton et al, 2005b). The cluster of breast cancer symptoms may include a lump, fatigue, pain, and insomnia (Gaston-Johansson et al, 1999; Banning, 2007). Recognition of a single, cancer-specific symptom may not be sufficient to produce an effect on survival from that cancer. Experiencing a few unexplained symptoms simultaneously, as a cluster, is perhaps more likely to have an effect on cancer survival because it may prompt people to seek medical help. 

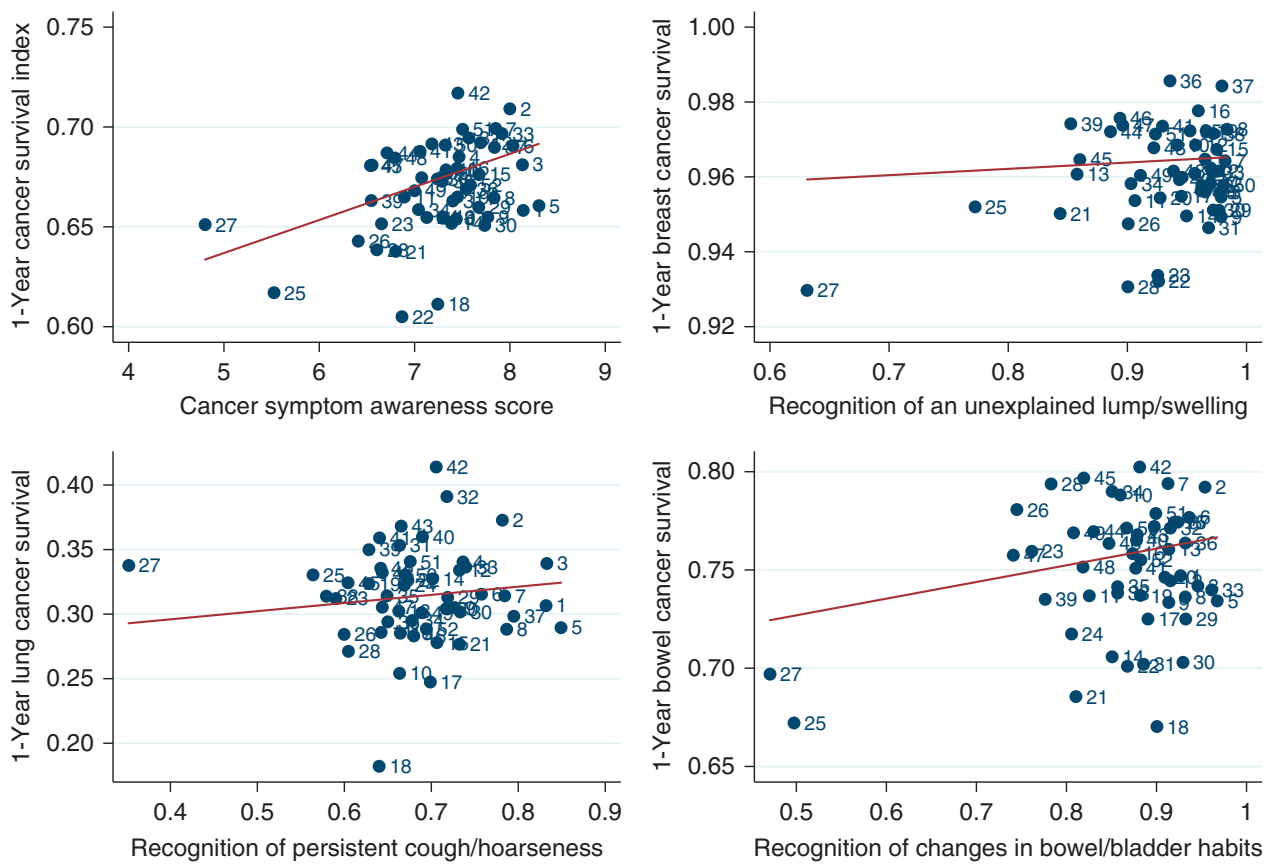

Figure 3. The position of 52 PCTs with regard (direction: from left to right) to the cancer survival index, breast, lung, and bowel cancer survival (y axis), the cancer awareness score, and the cancer-specific symptom: an unexplained lump/swelling, persistent cough/hoarseness, and a change in bowel/bladder habits in each PCT (x axis), standardised by age and sex, and weighted for the inverse variance of appropriate survival estimates.
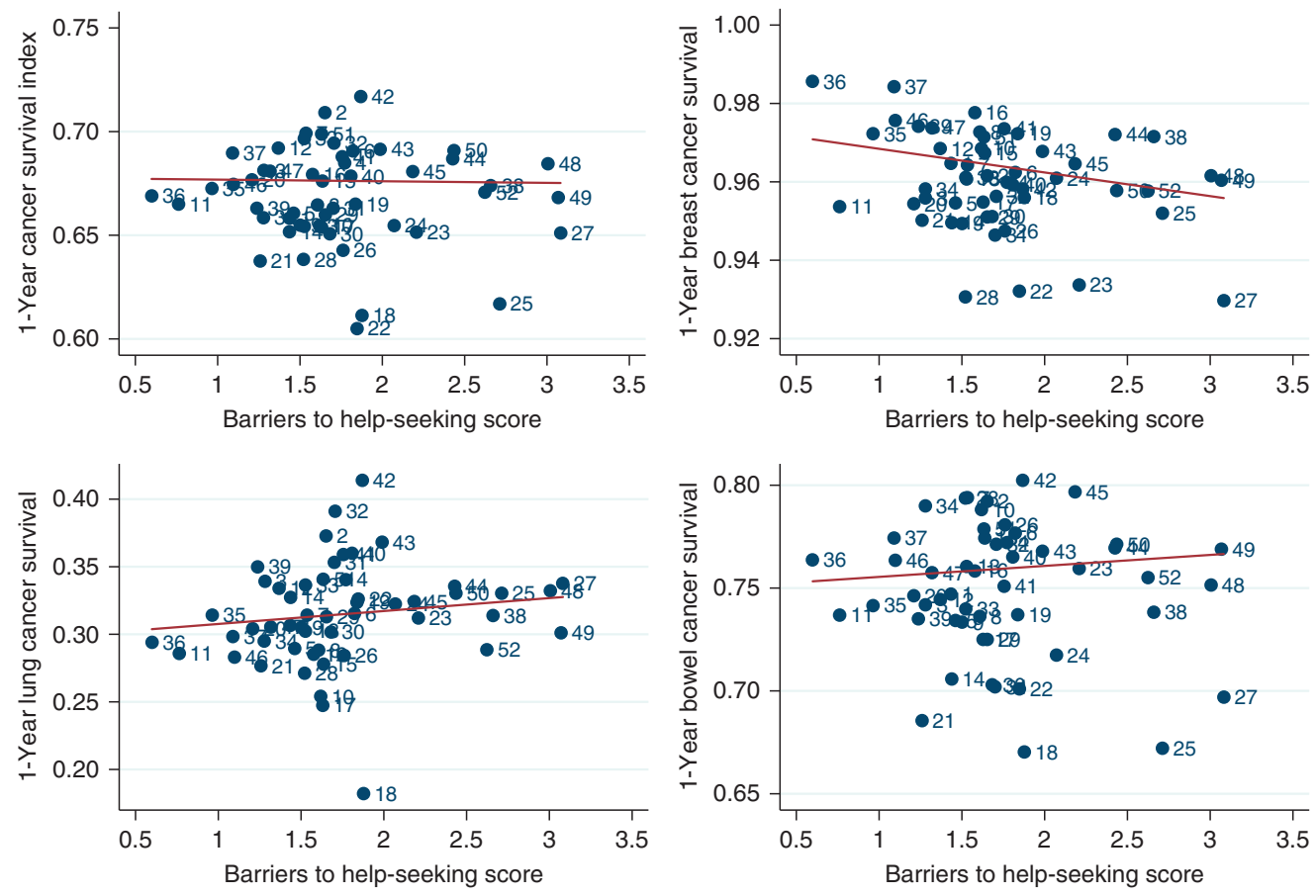

Figure 4. The position of 52 PCTs with regard (direction: from left to right) to the cancer survival index, breast, lung, and bowel cancer survival (y axis), standardised by age and sex, and weighted for the inverse variance of appropriate survival estimates.

The barriers score was not associated with the cancer survival index, but it was associated with breast cancer survival. This could be because breast cancer survival was assessed for women only, and there is evidence that women are more likely to report barriers to help seeking than men (Niksic et al, 2015). Women may perceive numerous reasons to deter them from seeking medical help, imposed by sociocultural norms. Female breasts have a social symbolism, linked with their maternal and sexual function. Therefore, breast cancer may be perceived as a violation of femininity, and a source of shame and stigma (Wong and King, 2008). Niksic et al (2015) found that women have 20\% higher odds than men to report that they would be put off consulting a doctor because of embarrassment, worry about wasting the doctor's time, and perceived difficulty in talking to the doctor. 
Table 2. Linear regression coefficients estimating the relationship between cancer survival indices and cancer awareness (score and individual symptoms) and barriers to help seeking (score and individual barriers) at PCT level

\begin{tabular}{|c|c|c|c|c|}
\hline Independent variables & $\begin{array}{l}\text { Overall cancer } \\
\text { survival index }\end{array}$ & Breast cancer survival & Lung cancer survival & Bowel cancer survival \\
\hline Awareness score & $1.56(0.56 ; 2.57)$ & $0.17(-0.38 ; 0.71)$ & $0.58(-1.34 ; 2.51)$ & $0.86(-0.58 ; 2.30)$ \\
\hline Unexplained lump/swelling & $0.12(0.01 ; 0.24)$ & $0.01(-0.06 ; 0.08)$ & $0.02(-0.19 ; 0.23)$ & $0.05(-0.12 ; 0.22)$ \\
\hline Unexplained persistent pain & $0.06(-0.04 ; 0.15)$ & $0.02(-0.03 ; 0.07)$ & $0.02(-0.15 ; 0.20)$ & $0.01(-0.12 ; 0.14)$ \\
\hline Unexplained bleeding & $0.11(0.01 ; 0.21)$ & $0.00(-0.05 ; 0.05)$ & $0.04(-0.14 ; 0.23)$ & $0.05(-0.09 ; 0.19)$ \\
\hline Persistent cough/hoarseness & $0.09(0.01 ; 0.16)$ & $0.00(-0.04 ; 0.04)$ & $0.04(-0.09 ; 0.18)$ & $0.07(-0.04 ; 0.17)$ \\
\hline Change in bowel/bladder habits & $0.12(0.04 ; 0.16)$ & $0.01(-0.03 ; 0.05)$ & $0.03(-0.11 ; 0.17)$ & $0.09(-0.02 ; 0.19)$ \\
\hline Difficulty in swallowing & $0.08(0.02 ; 0.14)$ & $0.00(-0.03 ; 0.03)$ & $0.05(-0.06 ; 0.17)$ & $0.06(-0.02 ; 0.15)$ \\
\hline Change in the appearance of a mole & $0.14(0.07 ; 0.20)$ & $0.02(-0.02 ; 0.05)$ & $0.06(-0.07 ; 0.20)$ & $0.09(-0.01 ; 0.19)$ \\
\hline Sore that does not heal & $0.05(-0.00 ; 0.11)$ & $0.01(-0.02 ; 0.04)$ & $0.01(-0.11 ; 0.10)$ & $-0.01(-0.08 ; 0.07)$ \\
\hline Unexplained weight loss & $0.12(0.04 ; 0.20)$ & $0.02(-0.02 ; 0.06)$ & $0.05(-0.10 ; 0.21)$ & $0.10(-0.01 ; 0.23)$ \\
\hline Barriers score & $-0.14(-1.28 ; 0.99)$ & $-0.66(-1.20 ;-0.11)$ & $0.94(-1.03 ; 2.91)$ & $0.05(-1.56 ; 1.67)$ \\
\hline Too embarrassed & $-0.06(-0.14 ; 0.02)$ & $-0.05(-0.09 ;-0.01)$ & $-0.01(-0.17 ; 0.14)$ & $-0.07(-0.19 ; 0.04)$ \\
\hline Too scared & $0.00(-0.08 ; 0.09)$ & $-0.02(-0.06 ; 0.03)$ & $0.00(-0.15 ; 0.15)$ & $0.03(-0.14 ; 0.09)$ \\
\hline Not confident to talk & $-0.06(-0.17 ; 0.05)$ & $-0.05(-0.11 ; 0.00)$ & $0.04(-0.16 ; 0.25)$ & $-0.12(-0.28 ; 0.04)$ \\
\hline Worry about what GP may find & $0.03(-0.04 ; 0.09)$ & $-0.02(-0.05 ; 0.02)$ & $0.06(-0.06 ; 0.18)$ & $0.02(-0.08 ; 0.11)$ \\
\hline Worry about other things & $-0.03(-0.12 ; 0.05)$ & $-0.07(-0.11 ;-0.02)$ & $0.07(-0.08 ; 0.23)$ & $0.02(-0.11 ; 0.15)$ \\
\hline Transport difficulties & $-0.09(-0.24 ; 0.06)$ & $-0.11(-0.18 ;-0.03)$ & $0.03(-0.22 ; 0.32)$ & $-0.01(-0.23 ; 0.21)$ \\
\hline Too busy & $0.03(-0.13 ; 0.06)$ & $-0.07(-0.11 ;-0.02)$ & $0.07(-0.10 ; 0.23)$ & $0.04(-0.09 ; 0.18)$ \\
\hline Worry about wasting GP's time & $0.04(-0.03 ; 0.10)$ & $-0.04(-0.07 ;-0.01)$ & $0.03(-0.08 ; 0.14)$ & $0.05(-0.04 ; 0.14)$ \\
\hline Difficulty talking to GP & $-0.08(-0.18 ; 0.03)$ & $-0.06(-0.11 ;-0.00)$ & $-0.04(-0.23 ; 0.16)$ & $-0.15(-0.30 ; 0.01)$ \\
\hline Difficulty making appointment & $-0.01(-0.09 ; 0.07)$ & $-0.06(-0.09 ;-0.02)$ & $0.07(-0.07 ; 0.21)$ & $-0.01(-0.12 ; 0.11)$ \\
\hline \multicolumn{5}{|c|}{$\begin{array}{l}\text { Abbreviations: GP = general practitioner/doctor; PCT = primary care trust. Weights for all cancer survival estimates were used in models where all cancers survival index was an outcome, and } \\
\text { cancer-specific weights were used in models where outcomes were breast, lung, and bowel cancer, respectively. All awareness and barriers scores (and individual symptoms/barriers) were } \\
\text { standardised for age and sex in each PCT. Estimates in bold were statistically significant at } P<0.05 \text { level ( } 95 \% \text { confidence interval). }\end{array}$} \\
\hline
\end{tabular}

These barriers were found to have a strong negative association with breast cancer survival.

We also need to acknowledge that the regression coefficients were statistically significant for most cancer symptoms in relation to the cancer survival index, but not for site-specific indices. This may be because of several reasons. First, an attenuation effect because of lower reliability, noting that many of the bowel cancer coefficients are approximately two-thirds the size of the overall coefficients. Second, good matching between the survival index, which included different types of cancer, and awareness score, which included different types of cancer symptoms. For example, it would be surprising if we observed that 'difficulty in swallowing' was associated with breast cancer survival. However, statistically significant association of this symptom with the cancer survival index is not surprising because survival from oesophageal cancer is included in this index. Third, survival from sitespecific cancers was not associated with awareness score, as expected, given that this score included a range of different symptoms that were not necessarily relevant for individual cancer sites. Fourth, breast, lung, and bowel cancer survival indices may have lower statistical power to detect effects of cancer symptom awareness and barriers on survival.

Furthermore, the coefficients for the barriers score for overall cancer survival index were close to zero, with the coefficients for breast cancer survival generally negative $(P<0.05)$, and for lung and bowel cancer generally positive (although not statistically significant). Therefore, it is possible that there was some cancelling out effect in that the barriers that were harmful for breast cancer survival may well have been protective for the other two cancers. Finally, the combination of positive and negative coefficients between overall cancer survival index and different barriers to help seeking suggests that the use of the aggregate barriers score may not be warranted. Some barriers may be associated with prompt help seeking, whereas other barriers may prolong interval to the first medical consultation. If this is true, different barriers to help seeking need to be analysed separately in order to understand the mechanism behind them and their relationship with cancer survival.

Further studies are required to confirm or refute these findings. More specifically, future studies should assess whether the observed associations exist at the individual level, and explore the reasons driving these results, such as educational attainment, ethnicity, number of doctors per PCT, or access to health-care services. Researchers should also focus on exploring whether gender differences in cancer awareness and barriers to help seeking could account for some of the differences in survival from the most common types of cancer. It is necessary to understand the role of different barriers to help seeking in cancer survival, and which mechanisms drive these differences. Understanding whether experiencing a cluster of cancer symptoms prompts or hinders help seeking and whether it is associated with cancer survival would be useful.

\section{CONCLUSIONS AND IMPLICATIONS}

Our study suggests that higher cancer symptom awareness is associated with better cancer survival that may inform future health campaigns and policy decision makers. We highlighted areas for improvement, and the relative position of each of the 52 PCTs with regard to cancer awareness, barriers to help seeking, and cancer survival. Future campaigns should help people to recognise early symptoms of different types of cancer and encourage preventive health behaviour, especially in socioeconomically deprived areas. Efforts should be made to alleviate 
barriers to seeking medical help in women with symptoms of breast cancer.

\section{ACKNOWLEDGEMENTS}

This study is part of a $\mathrm{PhD}$ programme funded by the Policy Research Unit in Cancer Awareness, Screening, and Early Diagnosis, which in turn receives funding from the Department of Health Policy Research Programme. It is collaboration between researchers from seven institutions: Queen Mary University of London, UCL, King's College London, London School of Hygiene and Tropical Medicine, Hull York Medical School, Durham University, and Peninsula Medical School.

\section{CONFLICT OF INTEREST}

The authors declare no conflict of interest.

\section{REFERENCES}

Banning M (2007) Advanced breast cancer: aetiology, pathogenesis and treatment. Cancer Nurs Pract 6(3): 35-39.

Berrino F, De Angelis R, Sant M, Rosso S, Lasota MB, Coebergh JW, Santaquilani M (2007) Survival for eight major cancers and all cancers combined for European adults diagnosed in 1995-1999: results of the EUROCARE-4 study. Lancet Oncol 8(9): 773-783.

Bojke C, Gravelle H, Wilkin D (2001) Is bigger better for primary care groups and trusts? BMJ 322: 599-602.

Cancer Research UK (2015) Be Clear on Cancer. Available at http:// www.cancerresearchuk.org/health-professional/early-diagnosis-activities/ be-clear-on-cancer (accessed on 12 April 2015).

Cattell V (2001) Poor people, poor places, and poor health: the mediating role of social networks and social capital. Soc Sci Med 52(10): 1501-1516.

Cheyne L, Taylor A, Milton R, Fear J, Callister M (2013) Social deprivation does not affect lung cancer stage at presentation or disease outcome. Lung Cancer 81(2): 247-251.

Coleman M, Forman D, Bryant H, Butler J, Rachet B, Maringe C, Nur U, Tracey E, Coory M, Hatcher J, McGahan C, Turner D, Marrett L, Gjerstorff M, Johannesen T, Adolfsson J, Lambe M, Lawrence G, Meechan D, Morris E, Middleton R, Steward J, Richards M. The ICBP Module Working Group (2011) Cancer survival in Australia, Canada, Denmark, Norway, Sweden, and the UK, 1995-2007 (the International Cancer Benchmarking Partnership): an analysis of population-based cancer registry data. Lancet 377: 127-138.

Coleman MP, Rachet B, Woods LM, Mitry E, Riga M, Cooper N, Quinn MJ, Brenner H, Esteve J (2004) Trends and socioeconomic inequalities in cancer survival in England and Wales up to 2001. Br J Cancer 90(7): 1367-1373.

Department for Communities and Local Government (2011) English indices of deprivation 2010: PCT summaries. Department for Communities and Local Government. Available at https://www.gov.uk/government/ publications/english-indices-of-deprivation-2010 (accessed on 3 November 2015).

Department of Health (2000) The NHS Cancer Plan: A Plan for Investment, a Plan for Reform. Department of Health: London, UK.

Department of Health (2011) Improving Outcomes: A Strategy for Cancer. Department of Health: London.

Department of Health (2014) Improving Outcomes: A Strategy for Cancer, Department of Health NE, Public Health England (ed.). Department of Health: London.

Dixon-Woods M, Cavers D, Agarwal S, Annandale E, Arthur A, Harvey J, Hsu R, Katbamna S, Olsen R, Smith L (2006) Conducting a critical interpretive synthesis of the literature on access to healthcare by vulnerable groups. BMC Med Res Methodol 6(1): 35.

East London NHS Trust (2013) Summary of the Health and Wellbeing Strategies for the City of London and the London Boroughs of Hackney, Newham and Tower Hamlets. East London NHS Foundation Trust:
London, UK. Available at https://www.elft.nhs.uk/uploads/files/1/ About/Our\%20Board/Trust\%20Board\%20Meetings/Trust\%20Board\%20 Meeting\%20Papers\%202013/September\%202013/TBD-2013-09-26\%20 Summary\%20of\%20Health\%20\&\%20Wellbeing\%20Strategies.pdf (accessed on 15 June 2015).

Environmental Systems Research Institute (2014) ArcGIS for Desktop Advanced 10.2: ESRI.

Ferlay J, Steliarova-Foucher E, Lortet-Tieulent J, Rosso S, Coebergh J, Comber H, Forman D, Bray F (2013) Cancer incidence and mortality patterns in Europe: estimates for 40 countries in 2012. Eur J Cancer 49(6): 1374-1403.

Forbes LJL, Atkins L, Thurnham A, Layburn J, Haste F, Ramirez AJ (2011) Breast cancer awareness and barriers to symptomatic presentation among women from different ethnic groups in East London. Br J Cancer 105(10): 1474-1479.

Forbes LJL, Simon AE, Warburton F, Boniface D, Brain KE, Dessaix A, Donnelly C, Haynes K, Hvidberg L, Lagerlund M, Lockwood G, Tishelman C, Vedsted P, Vigmostad MN, Ramirez AJ, Wardle J (2013) Differences in cancer awareness and beliefs between Australia, Canada, Denmark, Norway, Sweden and the UK (the International Cancer Benchmarking Partnership): do they contribute to differences in cancer survival? Br J Cancer 108(2): 292-300.

Gaston-Johansson F, Fall-Dickson JM, Bakos AB (1999) Fatigue, pain, and depression in pre-autotransplant breast cancer patients. Cancer Pract 7(5): 240-247.

Goodwin R, Holme S, Roberts D (2004) Variations in registration of skin cancer in the United Kingdom. Clin Exp Dermatol 29(3): 328-330.

Hamilton W, Peters TJ, Round A, Sharp D (2005a) What are the clinical features of lung cancer before the diagnosis is made? A population based case-control study. Thorax 60: 1059-1065.

Hamilton W, Round A, Sharp D, Peters T (2005b) Clinical features of colorectal cancer before diagnosis: a population-based case-control study. Br J Cancer 93: 399-405.

Hiom S (2015) Diagnosing cancer earlier: reviewing the evidence for improving cancer survival. Br J Cancer 112(Suppl 1): S1-S5.

Hvidberg L, Wulff CN, Pedersen AF, Vedsted P (2014) Barriers to healthcare seeking, beliefs about cancer and the role of socio-economic position. A Danish population-based study. Prev Med 71: 107-113.

Ironmonger L, Ohuma E, Ormiston-Smith N, Gildea C, Thomson C, Peake M (2014) An evaluation of the impact of large-scale interventions to raise public awareness of a lung cancer symptom. Br J Cancer 112: 207-216.

Kim H-J, McGuire DB, Tulman L, Barsevick AM (2005) Symptom clusters: concept analysis and clinical implications for cancer nursing. Cancer Nurs 28(4): 270-282.

Macintyre S, Ellaway A, Cummins S (2002) Place effects on health: how can we conceptualise, operationalise and measure them? Soc Sci Med 55(1): 125-139.

Marmot M (1998) Improvement of social environment to improve health. Lancet 351(9095): 57.

Marmot MG, Stansfeld S, Patel C, North F, Head J, White I, Brunner E, Feeney A, Marmot M, Smith GD (1991) Health inequalities among British civil servants: the Whitehall II study. Lancet 337(8754): 1387-1393.

Møller H, Flatt G, Moran A (2011) High cancer mortality rates in the elderly in the UK. Cancer Epidemiol 35(5): 407-412.

Møller H, Sandin F, Bray F, Klint A, Linklater KM, Purushotham A, Robinson D, Holmberg L (2010) Breast cancer survival in England, Norway and Sweden: a population-based comparison. Int J Cancer 127(11): 2630-2638.

Møller H, Sandin F, Robinson D, Bray F, Klint Å, Linklater KM, Lambert PC, Påhlman L, Holmberg L, Morris E (2012) Colorectal cancer survival in socioeconomic groups in England: variation is mainly in the short term after diagnosis. Eur J Cancer 48(1): 46-53.

NCIN (2013) Non-Melanoma Skin Cancer in England, Scotland, Northern Ireland, and Ireland. NCIN Data Briefing: National Cancer Intelligence Network.

NHS (2012) NHS Commissioning Board: Local area teams. Available at http:// www.networks.nhs.uk/nhs-networks/respiratory-leads/documents/ NHSCB\%20LATs\%20-\%20Specialised\%20Commissioning.pdf (accessed on 29 April 2013).

Niksic M, Rachet B, Warburton F, Forbes L (2016) Ethnic differences in cancer symptom awareness and barriers to seeking medical help in England. Br J Cancer 115: 136-144. 
Niksic M, Rachet B, Warburton F, Wardle J, Ramirez A, Forbes L (2015) Cancer symptom awareness and barriers to symptomatic presentation in England-are we clear on cancer? Br J Cancer 113(3): 533-542.

Nur U, Quaresma M, De Stavola B, Peake M, Rachet B (2015) Inequalities in non-small cell lung cancer treatment and mortality. J Epidemiol Community Health 69(10): 985-992.

Office for National Statistics (2012a) Cancer Incidence and Mortality in the United Kingdom, 2008-2010. UK Office for National Statistics: London, UK. Available at http://webarchive.nationalarchives.gov.uk/ 20160105160709/http://www.ons.gov.uk/ons/dcp171778_289890.pdf. (accessed on 12 May 2015).

Office for National Statistics (2012b) Index of Cancer Survival for Primary Care Trusts in England: Patients Diagnosed 1996-2010 and Followed up to 2011. Office for National Statistics. Available at http://www.ons.gov.uk/ ons/rel/cancer-unit/combined-cancer-survival-by-primary-care-trusts/ patients-diagnosed-1996-2010-followed-up-to-2011/stb-index-of-cancersurvival-by-pct-s.html.

Office for National Statistics (2012c) Index of Cancer Survival for Primary Care Trusts in England: Patients Diagnosed 1996-2010 and Followed up to 2011. Office of National Statistics: London. Available at http:// www.ons.gov.uk/ons/dcp171778_292580.pdfhttp://www.ons.gov.uk/ons/ publications/re-reference-tables.html? edition=tcm\%3A77-285389 (accessed on 7 April 2012).

Pashayan N, Powles J, Brown C, Duffy S (2006) Excess cases of prostate cancer and estimated overdiagnosis associated with PSA testing in East Anglia. Br J Cancer 95(3): 401-405.

Perme MP, Stare J, Estève J (2012) On ESTIMATION IN RELATIVE SURVIVAL. Biometrics 68(1): 113-120.

Piantadosi S, Byar DP, Green SB (1988) The ecological fallacy. Am J Epidemiol 127(5): 893-904.

Popay J, Thomas C, Williams G, Bennett S, Gatrell A, Bostock L (2003) A proper place to live: health inequalities, agency and the normative dimensions of space. Soc Sci Med 57(1): 55-69.

Quaresma M, Coleman MP, Rachet B (2015) 40-year trends in an index of survival for all cancers combined and survival adjusted for age and sex for each cancer in England and Wales, 1971-2011: a population-based study. Lancet 385(9974): 1206-1218.
Quaresma M, Jakomis N, Gordon E, Carrigan C, Coleman M, Rachet B (2011) Index of Cancer Survival for Primary Care Trusts in England-Patients Diagnosed 1996-2009 and Followed up to 2010. Office for National Statistics.

Quaresma M, Whitehead S, Coleman MP, Rachet B (2012) Index of Cancer Survival for Primary Care Trusts in England: Patients Diagnosed 19962010 and Followed up to 2011. Office for National Statistics: London, UK. Available at http://webarchive.nationalarchives.gov.uk/20160105160709/http:// www.ons.gov.uk/ons/dcp171778_292580.pdf (accessed on 7 April 2012).

Rachet B, Ellis L, Maringe C, Chu T, Nur U, Quaresma M, Shah A, Walters S, Woods L, Forman D (2010) Socioeconomic inequalities in cancer survival in England after the NHS cancer plan. Br J Cancer 103(4): 446-453.

Richards M (2009) The National Awareness and Early Diagnosis Initiative in England: assembling the evidence. Br J Cancer 101(Suppl 2)): s1-s4.

Robb KA, Stubbings S, Ramirez A, Macleod U, Austoker J, Waller J, Hiom S, Wardle J (2009) Public awareness of cancer in Britain: A population based survey in adults. $\mathrm{Br} J$ Cancer 101: s18-s23.

Stubbings S, Robb KA, Waller J, Ramirez A, Austoker J, Macleod U, Hiom S, Wardle J (2009) Development of a measurement tool to assess public awareness of cancer. Br J Cancer 101: s13-s17.

Waller J, Robb KA, Stubbings S, Ramirez A, Macleod U, Austoker J, Hiom S, Wardle J (2009) Awareness of cancer symptoms and anticipated helpseeking among ethnic minority groups in England. Br J Cancer 101: s24-s30.

Walters S, Quaresma M, Coleman MP, Gordon E, Forman D, Rachet B (2011) Geographical variation in cancer survival in England, 1991-2006: an analysis by Cancer Network. J Epidemiol Community Health 65: 1044-1052.

Wong N, King T (2008) The cultural construction of risk understandings through illness narratives. J Consr Res 34(5): 579-594.

(c) (i) (2) This work is licensed under the Creative Commons c. ${ }_{\text {BY }}$ NG SA Attribution-Non-Commercial-Share Alike 4.0 International License. To view a copy of this license, visit http:// creativecommons.org/licenses/by-nc-sa/4.0/

Supplementary Information accompanies this paper on British Journal of Cancer website (http://www.nature.com/bjc) 